\title{
Physicochemical Properties of Indian Honey at Different Concentrations and Temperatures
}

\author{
Gurpreet Kaur, P.S. Tarsikka
}

Department of Mathematics, Statistics and Physics, Punjab Agricultural University, Ludhiana, Punjab, India

\begin{abstract}
Investigations were made on the effect of temperature $\left(20-70^{\circ} \mathrm{C}\right)$ on the physicochemical parameters like ultrasonic velocity, density, electrical conductivity and total soluble solids (TDS) of honey having various concentrations (100, 90, 80, 70 and 60 $(w / w) \%)$. Some other properties $\mathrm{pH}$, refractive index, ${ }^{\circ}$ Brix and moisture content were also measured at room temperature. Ultrasonic velocity, density, surface tension, bulk modulus and acoustic impedance were negatively influenced by temperature. However the other parameters increase with temperature. All the honey parameters except density were significantly varies with temperature and concentration at 5\% level of significance. A good correlation was obtained between electrical conductivity and TDS.
\end{abstract}

Keywords-Concentration, Electrical conductivity, Honey, Temperature, Ultrasonic velocity.

\section{INTRODUCTION}

Honey is a natural sweet complex food produced by honeybee and can be used by human without processing. The natural honey is supersaturated sugar solution, with $99 \%$ of its composition with sugars and water only [1][2]. The special status of honey among consumers is since ancient times because of its natural image and health benefits. Although, the major constituents of honey are nearly same, but the composition of honey is variable in the world and it depends upon geographical, seasonal, floral source, plant origin and storage conditions [3][4][5].

Adulteration of honey increases from last years for economic gain. Honey can be made poorer in quality by adding amounts of sucrose, commercial glucose, starch, chalk, gelatins, water and other substances. These artificial honeys often have similar taste and physical appearance as natural honeys, but they lack the medicinal and nutritional properties of natural honeys, because of the absence of the minor constituents that are present in natural honeys. This informs the need for the characterization of honey. However, some physicochemical properties of honeys that can be easily determined have been found to be helpful for comparison of natural honey samples from different locations and also serves as important indicators that can help to distinguish natural honey from artificial honey [6]. The International Honey Commission (IHC) has therefore proposed certain constituents like moisture content, sugar, acidity and viscosity as the quality criteria for honey. The effect of honey on light can also be useful for determining the type and quality of product.

Moisture content and acidity of honey play an important role in determining the overall characteristics of honey and final assessment of its quality [7]. Higher the moisture contents in honey, greater the possibility of yeast fermentation and thus the change of flavour and color of honey.

Ultrasonic waves are sound waves with higher frequency than the maximum that can be sensed by human ear. Propagation of ultrasonic waves through honey helps to determine its adulteration because mixing of adulterants will changes its physical properties such as density, viscosity and homogeneity etc., these properties have direct impact on the velocity of ultrasonic waves through the medium. Ultrasonic methods were used by Ratajski et al [8] to identify honey types. The ultrasonic velocity can be used with other properties, results in many important thermodynamic properties [9]. Electrical conductivity of honey shows great variability according to the floral origin and can be used for differentiating between honey samples [10]. The electrical conductivity of an aqueous solution is measure of its ability to carry out electrical current by means of ionic motion. Honey contains organic acids, minerals, ash content, proteins and mineral salts, which are ionizable in solution and have property to conduct electric current [11].

Total Dissolved Solids (TDS) is a measure of the combined content of all inorganic and organic substances in honey in molecular, ionized or colloidal solution form. There is a good correlation between electrical conductivity and TDS, indicating both parameters can be used to determine the honey purity [12].

The purpose of present study was to find the effect of temperature on the physicochemical parameters of honey like ultrasonic velocity, density, electrical conductivity and TDS, with varying concentrations. Various honey parameters such as moisture content, refractive index, $\mathrm{pH}$ 
and sugar content ( ${ }^{\circ}$ Brix) was also measured to distinguish the different concentrations.

\section{MATERIALS AND METHODS}

2.1 Honey sample and concentration preparation

Raw honey from the Brassica (Rapeseed) plant was taken for study. Since, raw honey will not contain any adulteration and the honey straight from hives was considered. The various honey concentrations was prepared with addition of distilled water and mixing till a uniform solution was obtained. Moisture content can easily be measured with a refractometer using its relation with refractive index (n) given by Abu-Jdayil et al [13] as:

$$
\text { Moisture } \%=608.277-395.743 \times n
$$

\subsection{Ultrasonic velocity}

Ultrasonic velocity was measured by using ultrasonic interferometer (Batra Trading Company, Dual frequency 1 and $3 \mathrm{MHz}$ ) with constant frequency of $1 \mathrm{MHz}$. The honey sample of prepared concentration was poured in the measuring cell and reading was noted from the ammeter with counts of three maxima. The different temperatures of honey were attained by circulation of water at specific temperature using temperature controlled water bath.

\subsection{Electrical conductivity and TDS}

Electrical conductivity and TDS of honey concentrations were measured using the DiST (Dissolved Solids Tester) by Hanna instruments (HI 98311). The calibration of meter was done each time before taking the reading with distilled water. Electrical conductivity and TDS were measured at constant temperature using water bath.

\subsection{Density}

To measure the density of honey concentrations, specific gravity method was used. To evaluate the effect of temperature, the gravity bottles were placed in the temperature controlled water bath with temperature regulation for 20 minutes at each temperature, so the honey samples will acquired the selected temperature.

\subsection{Refractive index}

The refractive index of honey concentrations was calculated by using the Abbe refractometer. The reading of refractive index was noted from scale by adjusting the cross wire of telescope of Abbe refractometer on region distinguishing the dark and light region at room temperature and then a temperature correction factor 0.00023 per ${ }^{\circ} \mathrm{C}$ for temperature greater than $20^{\circ} \mathrm{C}$ was applied to calculate the final value of refractive index.

\section{6 pH}

pH was measured with Hanna pH meter (Model HI73127). The calibration of $\mathrm{pH}$ meter was done before each reading with the standard buffer solutions (buffer 4 and 7).

\subsection{Determination of other physicochemical www.ijeab.com}

\section{parameters}

Some other properties (moisture content, surface tension, bulk modulus, adiabatic compressibility, acoustic impedance and intermolecular free length) were determined for honey concentrations at different temperatures by using the relations given in Table 1 .

Table.1: Calculation of some other properties

\begin{tabular}{|l|l|}
\hline Parameter & Formula used \\
\hline Surface tension $(\mathrm{N} / \mathrm{m})$ & $\sigma=6.33 \times 10^{-10} \rho \mathrm{v}^{1.5}$ \\
\hline Bulk modulus $\left(\mathrm{N} / \mathrm{m}^{2}\right)$ & $\mathrm{K}=\rho \times \mathrm{v}^{2}$ \\
\hline Adiabatic compressibility $\left(\mathrm{m}^{2} \mathrm{~N}^{-1}\right)$ & $\beta=1 /\left(\rho \times \mathrm{v}^{2}\right)$ \\
\hline Acoustic impedance $\left(\mathrm{Ns} / \mathrm{m}^{3}\right)$ & $\mathrm{Z}=\mathrm{v} \times \rho$ \\
\hline Intermolecular free length $(\AA)$ & $\mathrm{L}=\mathrm{K}_{\mathrm{J}} \times \beta^{1 / 2}$ \\
\hline
\end{tabular}

Where $\mathrm{n}=$ refractive index

$\rho=$ density

$\mathrm{v}=$ ultrasonic velocity

$\mathrm{K}_{\mathrm{J}}=$ temperature dependent Jacobson's constant whose value is calculated from relation,

$$
\mathrm{K}_{\mathrm{J}}=(93.875+0.375 \mathrm{~T}) \times 10^{-8}
$$

Where $\mathrm{T}$ is the absolute temperature and this constant is independent of the nature of liquid used as given by Ernest and Kavitha [14].

\subsection{Statistical analysis}

The obtained results from the experiments were tested for its significance using one way analysis of variance (ANOVA) at $5 \%$ level of significance, by the software SPSS version 20.0.

\section{RESULTS AND DISCUSSION}

Table 2 shows some physicochemical properties of the five analyzed honey concentrations. With the increase in moisture content of honey samples the refractive index and ${ }^{\circ}$ Brix decrease, which implies that the passage of light through honey becomes faster with increase in moisture content. The decrease in sugar content with moisture content increase shows the reduction in bending of light. The overall sum of the moisture and sugar content constitute (95-99) \% and the remaining (5-1)\% could be attributed to non sugar components of these concentrations. The $\mathrm{pH}$ value obtained for honey concentrations is consistent with literature data [15] and it is not showing any considerable change because of high acidity.

Table.2: Physicochemical parameters of honey

$$
\text { concentrations }
$$

\begin{tabular}{|c|c|c|c|c|c|}
\hline \multirow{2}{*}{ Parameter } & \multicolumn{5}{|c|}{ Honey concentrations ((w/w) \%) } \\
\cline { 2 - 6 } & 100 & 90 & 80 & 70 & 60 \\
\hline $\begin{array}{c}\text { Refractive } \\
\text { index }\end{array}$ & 1.488 & 1.465 & 1.452 & 1.438 & 1.411 \\
\hline $\begin{array}{c}{ }^{\circ} \text { Brix } \\
\begin{array}{c}\text { Moisture } \\
\text { content }(\%)\end{array}\end{array}$ & 78.2 & 69.6 & 62.0 & 56.0 & 50.1 \\
\hline
\end{tabular}

Page | 992 


\begin{tabular}{|c|c|c|c|c|c|}
\hline $\begin{array}{c}\text { Sugar + } \\
\text { moisture } \\
\text { content \% }\end{array}$ & 97.61 & 98.42 & 95.66 & 95.20 & 99.99 \\
\hline $\mathrm{pH}$ & 3.30 & 3.35 & 3.28 & 3.33 & 3.34 \\
\hline
\end{tabular}

\subsection{Effect of temperature on ultrasonic velocity}

The measured values of ultrasonic velocity in honey samples as a function of selected temperatures and concentrations is expressed in the form of graph between ultrasonic velocities versus temperature at different concentrations as shown in Fig. 1. The ultrasonic velocity in honey samples decreases with the increase in temperature because the intermolecular free length increases with the increase of thermal energy [16]. Molecules at higher temperatures have more energy, thus they can vibrate faster and ultrasonic waves can travel more quickly. The decrease in ultrasonic velocity of honey with increase in quantity of the distilled water can be explained due to the presence of strong attraction between water and honey molecules after mixing [17]. In the case of distilled water, the ultrasonic velocity increases with increase in temperature. Because of the dominant decrease in density of water as temperature increase up to $70^{\circ} \mathrm{C}$. Similar results were reported by Ghaedian et al [18] and Benedito et al [19] for distilled water.

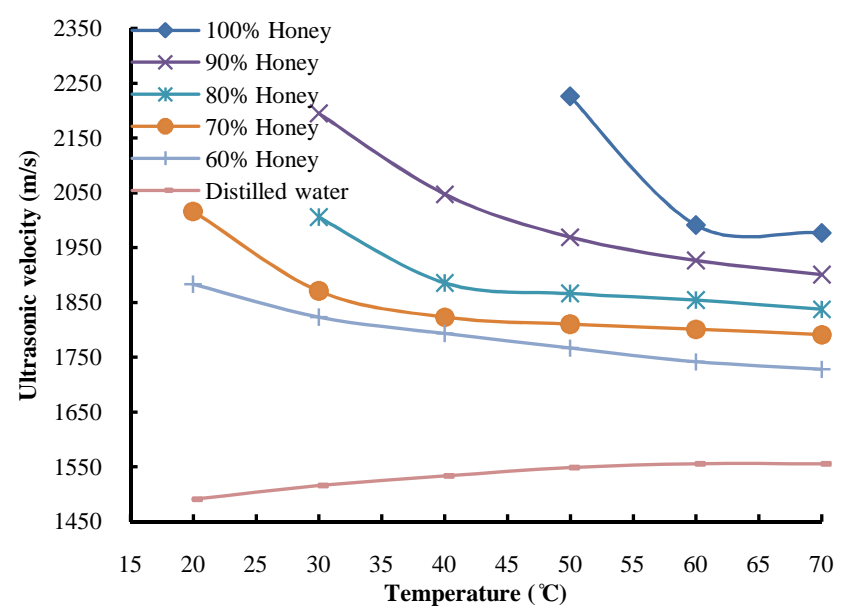

Fig..1:Variations of ultrasonic velocity at different temperatures

\subsection{Effect of temperature on electrical conductivity}

The values of electrical conductivity are expressed in a form of electrical conductivity versus temperature at various honey concentrations graphically as shown in Fig. 2. The electrical conductivity increased with the increase in the temperature as expected due to the increased ionic movement and is consisted with the literature data [20][21]. The values of electrical conductivity depend on the concentration and mobility of ions present in the honey solution. In the concentrations corresponding to the more diluted honey samples, the electrical conductivity increased as a result of increasing ion concentration up to

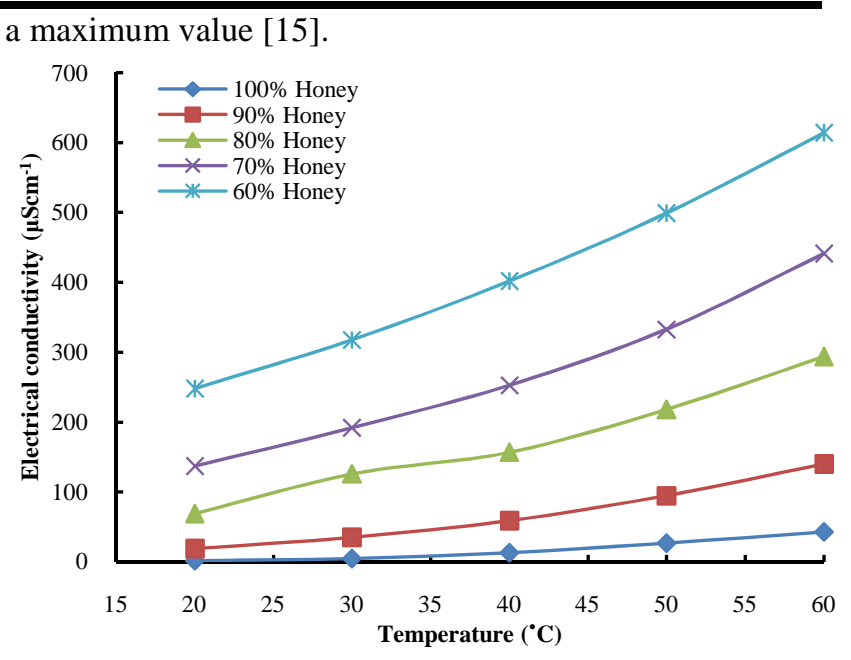

Fig. 2: Variations of electrical conductivity at different temperatures

\subsection{Effect of temperature on TDS}

The patterns of the TDS for honey samples are plotted graphically, TDS versus temperature at different concentrations as shown in Fig. 3. The increase in the TDS value can be explained due to breaking of the bonds in the honey molecules by acquiring the thermal energy supplied externally in the form of temperature or heat. The variation of TDS as the function concentration can be because when honey sample was mixed with the distilled water, due to interaction of honey molecules with water molecules a number of free molecules or ions were liberated in the solution.

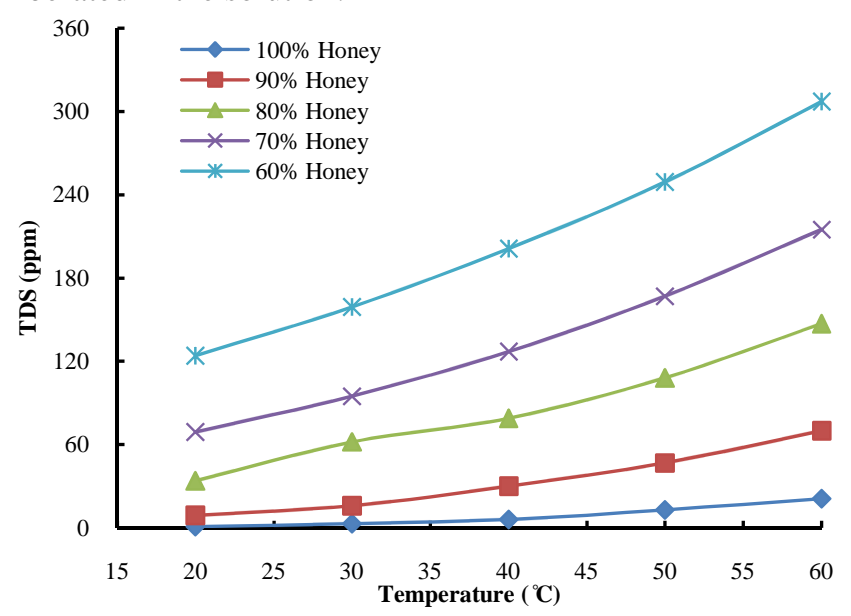

Fig.3: Variations of TDS at different temperatures

\subsection{Effect of temperature on density}

The density of honey decreases non-significantly for different temperatures and concentrations. The density of honey concentrations was observed higher then density of distilled water.

\subsection{Effect of temperature on surface tension}

Surface tensions for honey are plotted graphically as surface tension versus temperature at different concentrations shown in Fig. 4. The surface tension increases quadratically with increase in the concentration 
of honey which was also observed by Oroian [22]. Surface tension is influenced by mineral constituents and all other active minor honey constituents which may be surface active. The decrease in the value of surface tension shows that the surface molecules are less tightly bound as compared to inner honey molecules with the increase in temperature. Also, the sugar molecules are attracted more strongly by the liquid molecules. If this attraction exceeds that between the liquid molecules among themselves, it reduces the surface energy, resulting in a decrease in the surface tension of the solution [23].

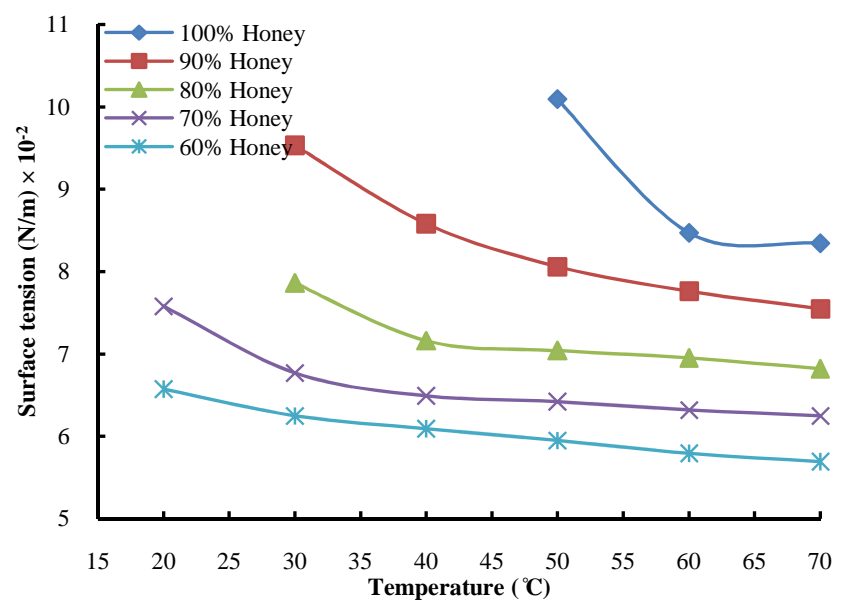

Fig. 4: Variations of surface tension at different temperatures

3.6 Effect of temperature on bulk modulus

The plot of bulk modulus versus temperature at different concentration is shown in Fig. 5. Bulk modulus is a measure of fluid's resistance to compressibility. The decrease in bulk modulus with increase in quantity of the distilled water is due to the presence of strong attraction between water and honey molecules after mixing [24]. With the addition of distilled water, the interactions between water and honey molecule causes increase in intermolecular free length and hence decrease in bulk modulus.

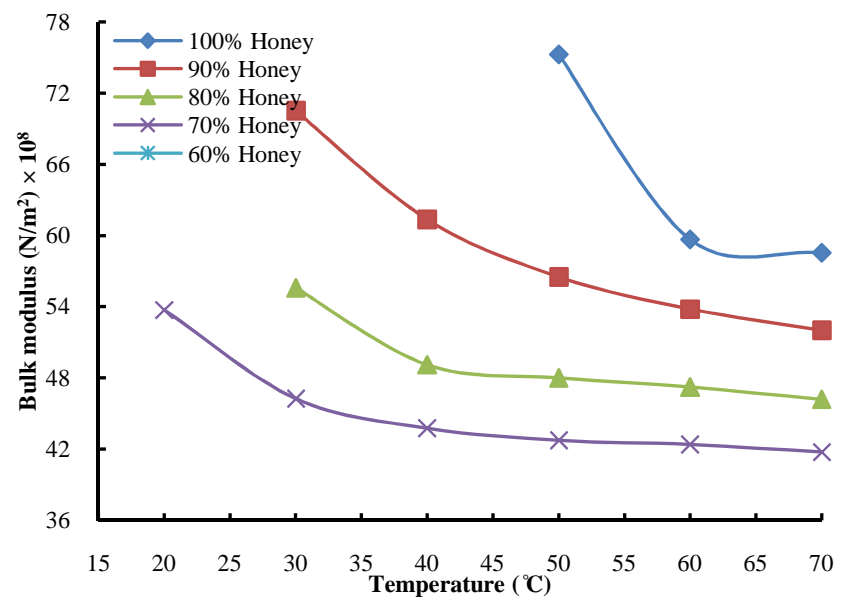

Fig. 5: Variations of bulk modulus at different temperatures
3.7 Effect of temperature on adiabatic compressibility Graphs were plotted as adiabatic compressibility versus temperature at different concentrations (shown in Fig. 6). The variation of adiabatic compressibility with temperature indicating loose packing of the molecules inside the shield, which may be brought about by the decreasing magnitude of interactions with increase in temperature [16]. The change in adiabatic compressibility with concentration is because of the interaction of the distilled water and honey molecules after mixing.

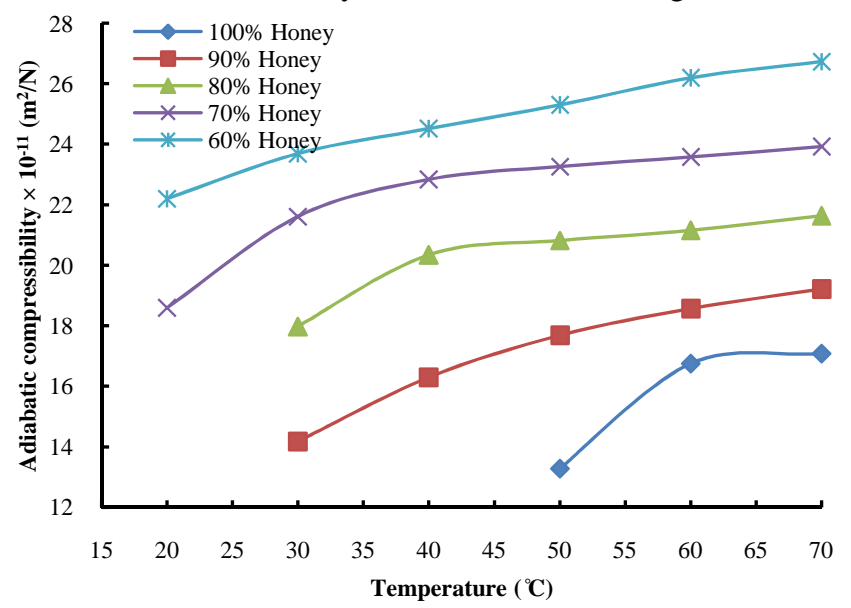

Fig. 6: Variations of adiabatic compressibility at different temperatures

\subsection{Effect of temperature on acoustic impedance}

The values of acoustic impedance are shown graphically as acoustic impedance versus temperature at various concentrations which are shown in Fig. 7. The decrease in acoustic impedance with temperature is due to the decrease in resistance. The decrease in ultrasonic velocity value with temperature indicates the easy flow of sounds waves through the honey sample and hence the acoustic impedance decreases [25]. The increase in adiabatic compressibility with concentration and hence the acoustic impedance decreases [24].

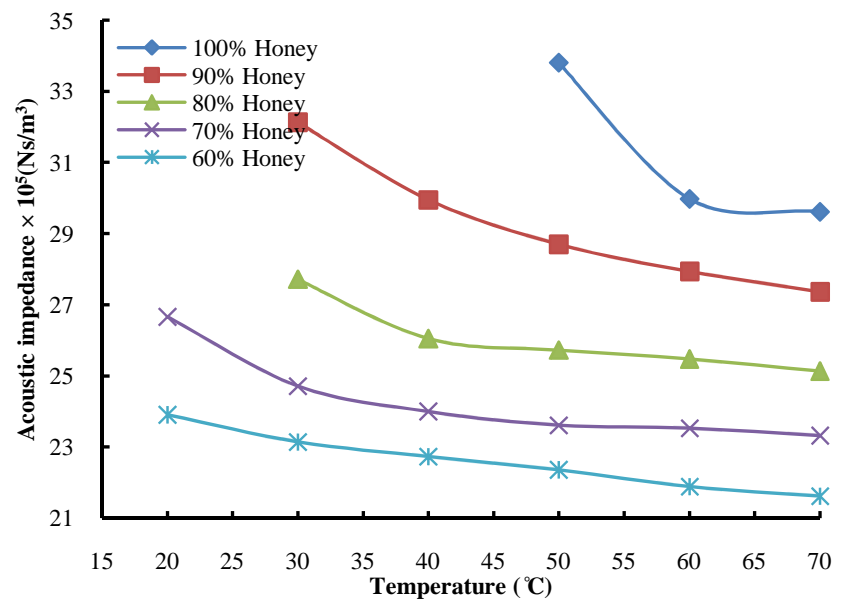

Fig. 7: Variations of acoustic impedance at different temperatures 


\subsection{Effect of temperature on intermolecular free length}

The intermolecular free length of molecule is both concentration and temperature dependent. The calculated value of intermolecular free length is expressed in form of intermolecular free length versus temperature graphically which is shown in Fig. 8. Intermolecular free length is the distance between the surfaces of the neighboring molecules. The influence of temperature increase can be attributed to ease of breaking of sugar bonds in the honey samples. The sugar molecules of the sample acquired the thermal energy from the applied temperature and hence which results in increasing intermolecular free length. Also, the addition of water to honey brings about exchange of the sugar-sugar hydrogen bonding with sugar-water hydrogen bonding [6].

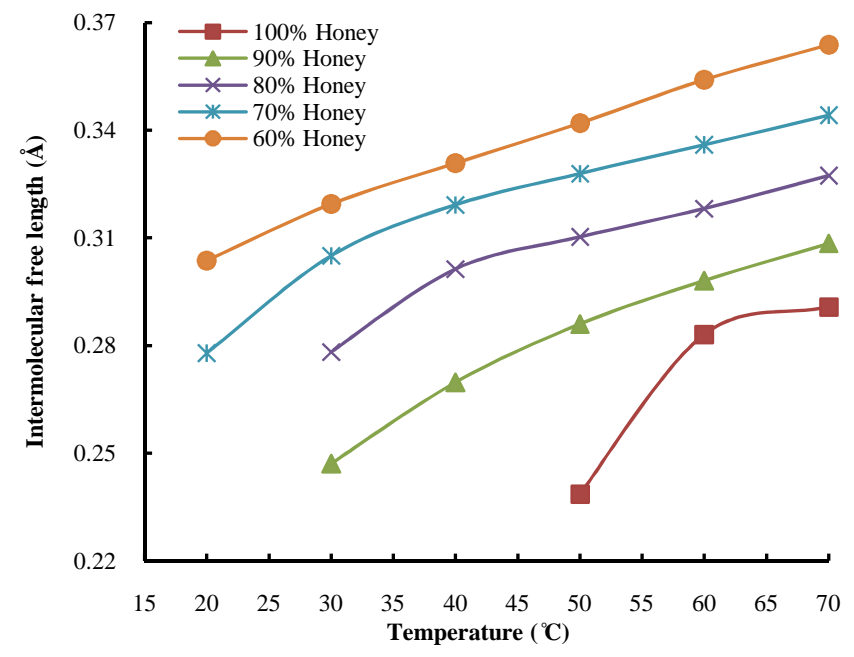

Fig. 8: Variations of intermolecular free length at different temperatures

\subsection{Correlation between electrical conductivity and TDS}

Since the electrical conductivity is a measure to the capacity of liquid to conduct electrical current, it is directly related to the concentration of salts dissolved in liquid, and therefore to TDS. Electrical conductivity and TDS of honey samples show the same behaviour with respect to temperature and concentrations. Thus, there is a good correlation between electrical conductivity and TDS, indicating that both parameters can be used to determine honey purity [12][26][27]. The correlation coefficient for electrical conductivity and TDS is found to be 1.000 and it is significant at $5 \%$ level of significance.

\section{CONCLUSIONS}

The variations in the temperature and concentration affect significantly the physicochemical properties (ultrasonic velocity, electrical conductivity, TDS, surface tension, bulk modulus, adiabatic compressibility, acoustic impedance, intermolecular free length) of honey. Thus, these properties can be used as an indicator of quality of honey at different levels of concentration and temperature. The set of complementary techniques used in the present study does not require chemical reactants or expensive equipments and gives improved characterization of the honeys of different regions and quality of product.

\section{REFERENCES}

[1] I. R. Siddiqui, "The sugars of honey", Adv Carbohydr Chem Biochem, vol. 25, pp.285-309, 1970.

[2] L. W. Doner, "The sugars of honey, a review", J Sci Food Agric, vol. 28, pp.443-456, 1977.

[3] S. Serrano, M. Villarejo, R. Espejo and M. Jordal, "Chemical and physical parameters of Andalusian honey", Food Chem, vol. 87, pp.619-625, 2004.

[4] V. Nanda, B. Sarkar, H. Sharma and A. Bawa, "Physicochemical properties and estimation of mineral content in honey produced from different plants in northern India", J Food Comp Anal, vol. 16, pp.613-619, 2003.

[5] M. C. Ciappini, M. B. Gatti, M. V. Divito, S. Gattuso and M. Gattuso, "Characterization of different floral origins honey samples from Santa $\mathrm{Fe}$ (Argentina) by palynological, physicochemical and sensory data", Apiacta, vol. 43, pp.25-36, 2008.

[6] O. O. James, M. A. Mesubi, L. A. Usman, S. O. Yeye, K. O. Ajanaku, K. O. Ogunniran, O. O. Ajani and T. O. Siyanbola, "Physical characterisation of some honey samples from north central Nigeria", Int J Physical Sci, vol. 4, pp.464-470, 2009.

[7] P. Nadezda, Z. B. Milica, J. Sandra, M. Zeljko, K. Brankica, B. Jelena and S. Sara, "Moisture and acidity as indicators of the quality of honey originating from Vojvodina region", Arh Vet Med, vol. 7, pp.99-109, 2014.

[8] A. Ratajski, Białobrzewski, F. Dajnowiec and S. Bakier, "The use of ultrasonic methods in the identification of honey types", Techn Sc, vol. 13, pp.22-29, 2010.

[9] M. P. Singh and R. K. Singh, "Correlation between ultrasonic velocity, surface tension, density and viscosity of ionic liquids", Fluid Phase Equilib, vol. 304, pp.1-6, 2011.

[10] K. Nigussie, P. A. Subramanian and G. Mebrahtu, "Physicochemical analysis of Tigray honey, an attempt to determine major quality markers of honey", B Chem Soc Ethiopia, vol. 26, pp.127-133, 2012.

[11] A. Terrab, M. J. Diez and F. J. Heredia, "Palynoloical, physicochemical and colour characterization of Moroccan honey”, Int J Food Sci

Page | 995 
Technol, vol. 38, pp.379-386, 2003.

[12] M. I. Khalil, M. Moniruzzaman, L. Boukraa, M. Benhanifia, M. A. Islam, M. N. Islam, S. A. Sulaiman and S. H. Gan, "Physicochemical and antioxidant properties of Algerian honey", Molecules, vol. 17, pp.11199-11215, 2012.

[13] B. Abu-Jdayil, G. A. Al-Majeed, KIM Al-Malah and S. J. Zaitoun, "Heat effect on rheology of light- and dark-colored honey", J Food Engg, vol. 51, pp.3338, 2002.

[14] S. Ernest and P. Kavitha, "Acoustical and excess thermodynamical parameters of sesame oil in different organic solvents", IjCEPr, vol. 2, pp.111115, 2011.

[15] C. Acquarone, P. Buera and B. Elizalde, "Pattern of $\mathrm{pH}$ and electrical conductivity upon honey dilution as a complementary tool for discriminating geographical origin of honeys", Food Chem, vol. 101, pp.695-703, 2007.

[16] A. B. Dikko, S. C. Ezike and E. Ike, "Ultrasonic velocity and some acoustical and thermodynamic parameters of multi-component liquid mixture at different temperatures", Int J Sci Engg Appl Sci, vol. 1, pp.454-458, 2015.

[17] S. S. J. Srinivas, K. B. B. Tulasi, R. K. Babu, K. Narendra and B. M. Sarath, "Studies of densities, viscosities and ultrasonic speeds of binary mixtures containing isopropyl alcohol and ketones at different temperatures", Int Lett Chem Phys Astron, vol. 15, pp.151-158, 2013.

[18] R. Ghaedian, J. N. Coupland, E. A. Decker and D. J. McClements, "Ultrasonic determination of fish composition", J Food Engg, vol. 35, pp.323-335, 1998.

[19] J. Benedito, A. Mulet, G. Clemente and J. V. Garcia-Perez, "Use of ultrasound for the composition assessment of olive mill waste water (alpechin)" Food Res Int, vol. 37, pp.595-601, 2004.

[20] W. Guo, Y. Liu, X. Zhu and H. Zhuang, "Sensing the water content of honey from temperaturedependent electrical conductivity", Meas Sci Technol, vol. 22, pp.1-5, 2011.

[21] T. Szczesna and C. H. Rybak, "The temperature correction factor for electrical conductivity of honey", J Apic Sci, vol. 48, pp.97-102, 2004.

[22] M. Oroian, "Measurement, prediction and correlation of density, viscosity, surface tension and ultrasonic velocity of different honey types at different temperatures", J Food Engg, vol. 119, pp.167-172, 2013.

[23] U. P. Shinde, S. S. Chougule, C. G. Dighavkar, B. S. Jagadale and D. K. Halwar, "Surface tension as a function of temperature and concentration of liquids", IJCPS, vol. 4, pp.1-7, 2015.

[24] G. R. Balaji, M. Prabhakaran, S. Rajasekar and P. S. Joseph, "Ultrasonic studies on molecular interactions in binary and ternary mixtures of benzophenone with n-alkanols and toluene", GRT, vol. 4, pp.1-8, 2014.

[25] P. K. Singh and S. C. Bhatt, "Investigation of acoustical parameters of polyvinyl acetate", Appl Phys Res, vol. 2, pp.35-45, 2010.

[26] M. Moniruzzaman, M. I. Khalil, S. A. Sulaiman and S. H. Gan, "Physicochemical and antioxidant properties of Malaysian honeys produced by Apis cerana, Apis dorsata and Apis mellifera", BMC Complement Altern Med, vol. 13, pp.43-55, 2013.

[27] A. H. Hamed, S. A. Dhahir and F. M. Abid, "Physiochemical properties for some kinds honey in Iraqi markets", Int J Interdiscip Res Innov, vol. 4, pp.28-33, 2014. 